\title{
Erratum to: Arabidopsis thaliana intramembrane proteases
}

\author{
Małgorzata Adamiec $^{1} \cdot$ Maria Ciesielska $^{1} \cdot$ Patrycja Zalaś $^{1} \cdot$ Robert Luciński $^{1}$
}

Published online: 2 August 2017

(C) Franciszek Górski Institute of Plant Physiology, Polish Academy of Sciences, Kraków 2017

\section{Erratum to: Acta Physiol Plant (2017) 39:146 \\ DOI 10.1007/s11738-017-2445-2}

Unfortunately, two reference citations were published incorrectly in the original publication of the article. In the last section before the Conclusion part, the 2nd and 3rd sentence should read as:

Studies performed on spp heterozygotes indicate that the protein is involved in pollen development and germination (Han et al. 2009). The SPPL1, SPPL2 and SPPL3 transcripts were detected in the tissues, roots, rosette leaves, cauline leaves, stems, flower-bud clusters, siliques and dry seeds (Tamura et al. 2008). The significant accumulation of all three transcripts was, however, observed during seed germination.

The online version of the original article can be found under doi:10.1007/s11738-017-2445-2.

Małgorzata Adamiec

malgorzata.adamiec@amu.edu.pl

1 Department of Plant Physiology, Faculty of Biology, Institute of Experimental Biology, Adam Mickiewicz University, Umultowska 89, 61-614 Poznań, Poland 